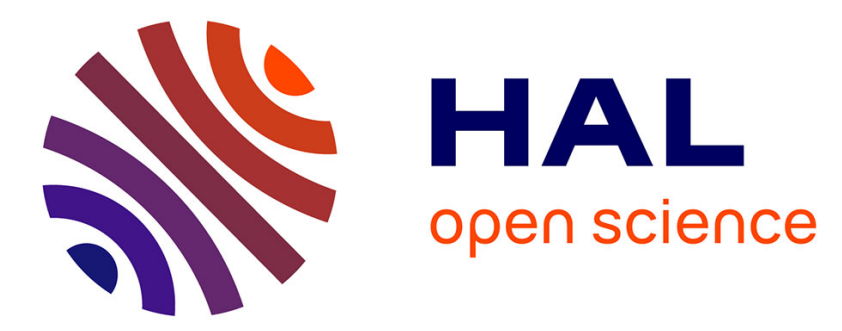

\title{
Self-assembly of a non-ionic surfactant onto a clay mineral for the preparation of hybrid layered materials \\ Régis Guégan
}

\section{To cite this version:}

Régis Guégan. Self-assembly of a non-ionic surfactant onto a clay mineral for the preparation of hybrid layered materials. Soft Matter, 2013, 9, pp.10913-10920. 10.1039/c3sm52337c . insu-00874712

\section{HAL Id: insu-00874712}

\section{https://hal-insu.archives-ouvertes.fr/insu-00874712}

Submitted on 18 Oct 2013

HAL is a multi-disciplinary open access archive for the deposit and dissemination of scientific research documents, whether they are published or not. The documents may come from teaching and research institutions in France or abroad, or from public or private research centers.
L'archive ouverte pluridisciplinaire HAL, est destinée au dépôt et à la diffusion de documents scientifiques de niveau recherche, publiés ou non, émanant des établissements d'enseignement et de recherche français ou étrangers, des laboratoires publics ou privés. 
Cite this: DOI: $10.1039 / c 3 s m 52337 c$

\title{
Self-assembly of a non-ionic surfactant onto a clay mineral for the preparation of hybrid layered materials
}

\author{
R. Guégan*ab
}

The adsorption of the tri-ethylene glycol mono-n-decyl ether $\left(C_{10} E_{3}\right)$ nonionic surfactant, characterized by its self-assembled lamellar phase above the critical micelle concentration ( $\mathrm{cmc}$ ), in a wide range of concentration, onto a layered clay mineral (montmorillonite) has been studied. $\mathrm{C}_{10} \mathrm{E}_{3}$ exhibits a high affinity for the montmorillonite (Mt) surface with an adsorption isotherm that differs strictly from previous studies on the adsorption of nonionic surfactants onto clay minerals for which a maximum of adsorption was reached below cmc. The self-organization in a lamellar phase changes the interaction potential between $\mathrm{C}_{10} \mathrm{E}_{3}$ and $\mathrm{Mt}$, a surface that favors the aggregation of normal bilayers which expands the interlayer space at wide values $(>40 \AA)$ ) while keeping the exchangeable $\mathrm{Na}^{+}$cations conferring dual hydrophilic-hydrophobic behavior for the hybrid layered materials. Depending on the $\mathrm{C}_{10} \mathrm{E}_{3}$ phase state (in monomers or in a lamellar phase), the adsorption leads to four distinct surfactant arrangements (lateral layers to normal tilted bilayers) within the interlayer space of Mt. The hybrid layered materials show a thermal stability at $350{ }^{\circ} \mathrm{C}$ with a collapse of their interlayer space at $13 \AA$ due to the degradation of the hydrocarbon chains of $\mathrm{C}_{10} \mathrm{E}_{3}$. FTIR during thermogravimetry analysis permits the identification of the portions of $\mathrm{C}_{10} \mathrm{E}_{3}$ corresponding to ethylene oxide groups in close interaction with the Mt surface.

Received 4th September 2013 Accepted 29th September 2013

DOI: 10.1039/c3sm52337c

www.rsc.org/softmatter aggregation onto the solid surface and/or for the preparation of hybrid organo-inorganic materials. ${ }^{9-13}$

Clay minerals such as montmorillonite (Mt) are layered materials, which show a large specific surface area and excellent adsorption properties for numerous chemical compounds. The adsorption of non-ionic surfactants and equivalent polymers onto clay minerals was intensively studied in the past and it was reported that the ion-dipole interaction corresponds to the main adsorption mechanism with the substitution of water molecules by nonionic organic molecules surrounding the exchangeable cations, whereas further studies stressed out the importance of both silanol and aluminol groups as main factors for the arrangement of surfactants and stability of prepared organoclays (OC). ${ }^{\mathbf{1 0 1 2 , 1 4 - 2 0}}$ Among the numerous studies conducted on the adsorption of nonionic surfactants such as $\mathrm{C}_{12} \mathrm{E}_{5}$, Brij, polyoxyethylenic (TX100), and polyethylene glycol (PEG) onto Mt, few studies focused on characterizing the adsorption in a wide range of concentration in the aggregation of surfactants onto clay minerals. Most of the previous investigations restrained the concentration range below $\mathrm{cmc}$ or near $\mathrm{cmc}$, for which the maximum of adsorption was reached and the resulting adsorption isotherms were fitted by a Langmuir-type equation. ${ }^{\mathbf{1 4 , 1 5}}$ In this way, although involving additional forces with the heterogeneous Mt surface, surfactant molecules aggregated by a bulk like micellization mechanism leading to full occupation of the whole accessible surface with lateral monolayer or bilayer arrangements. Nevertheless, Breen et al.
Institut des Sciences de la Terre d'Orléans, UMR 7327 CNRS-Université d'Orléans, $1 \mathrm{~A}$ Rue de la Férrolerie, 45071 Orléans Cedex 2, France. E-mail: regis.guegan@ univ-orleans.fr

${ }^{b}$ Graduate School of Creative Science and Engineering, Waseda University, Nishiwaseda 1-6-1, Shinjuku, Tokyo, 169-8050, Japan 
studied the adsorption under and above the cmc of TX100 on several Mt with different charge densities and nature of the countercations. ${ }^{21}$ Although the basal spacings of the resulting OC did not exceed $16 \AA$ corresponding to the intercalation of one or two lateral surfactant layers, the adsorption isotherms of the last nonionic surfactant, which forms spherical micelles beyond cmc, did not show any steady state. However, even at high loadings of TX100 and the use of $\mathrm{Na}^{+}$-Mt dispersions, TX100 was not intercalated in a micelle form within the interlayer space of the studied clay mineral.

Recently, the intercalation of a normal $\mathrm{C}_{10} \mathrm{E}_{3}$ bilayer in a natural Mt resulting in the condensation of a bulk lamellar phase above cmc has driven to a wide expansion of its interlayer space of about $37 \AA$, which strongly differs from previous studies. ${ }^{\mathbf{1 0}}$ This study, distinguishing from the previous way of preparing and obtaining OC, points out the importance of the surfactant state (single molecules $v s$. liquid crystalline phase) in the adsorption of nonionic species onto the heterogeneous surface, which may occur in a micelle form rather than involving monomers. Moreover, this last result also supports previous observations on the intercalation of a polyhedral oligomeric silsesquioxane (POSS) cationic surfactant, which was self-organized in bilayers or paraffin structures far below the cation exchange capacity (CEC) and its aggregation mechanism was due to its bulk state according to the contributors of these studies. ${ }^{22,23}$

Thus, the aim of this study is to elucidate the role of the nonionic surfactant state in the adsorption of $\mathrm{C}_{10} \mathrm{E}_{3}$ onto $\mathrm{Na}^{+}-$ Mt. For this purpose, the small angle X-ray scattering (SAXS) technique, adsorption isotherms and Fourier transform infrared spectroscopy (FTIR) were applied for a series of nonionic OC prepared from a wide concentration range, which is below and beyond the critical micellar concentration ( $\mathrm{cmc}$ ) of $\mathrm{C}_{10} \mathrm{E}_{3}$ in aqueous solution. This is expected to provide valuable information on the confinement of non-ionic surfactants into clay minerals and on the relationship between the bulk surfactant state (monomers or self-assembled organization) in solution and intercalated structures. Moreover, the thermal analysis of the resulting $\mathrm{C}_{10} \mathrm{E}_{3}$-Mt layered composites was performed in order to probe the stability of the surfactant arrangement and elucidate as well the portions of $\mathrm{C}_{10} \mathrm{E}_{3}$ in close interaction with the Mt surface.

\section{Materials and methods}

\section{Materials}

Wyoming sodium montmorillonite $\left(\mathrm{Na}^{+}-\mathrm{Mt}\right)$, obtained from the Source Clay Minerals Repositery, University of Missouri (Columbia, MO), was used in this study. This $\mathrm{Na}^{+}-\mathrm{Mt}$ has a cation exchange capacity (CEC) of 80 mequiv. per $100 \mathrm{~g}$ clay, and a measured specific surface area of $660 \mathrm{~m}^{2} \mathrm{~g}^{-1} \cdot{ }^{24}$ The clay mineral was fractioned to $<2 \mu \mathrm{m}$ by gravity sedimentation, purified and exchange of $\mathrm{Na}$ was performed using well-established procedures in clay science. ${ }^{25}$

Tri-ethylene glycol mono- $n$-decyl ether $\left(\mathrm{C}_{10} \mathrm{E}_{3}\right)$ nonionic surfactant, purchased from Nikko Chemicals, Inc., (Tokyo, Japan), assumed to have a purity of $>99.8 \%$ was used without further purification. In aqueous solution, a lamellar $\left(\mathrm{L}_{\alpha}\right)$ phase exists at room temperature with a $\mathrm{C}_{10} \mathrm{E}_{3}$ bilayer thickness close to $27.6 \AA$ and substantially less than twice the length of surfactant molecules. This indicates that the extended hydrocarbon chains present a tilt angle of $30-40^{\circ}$ with the hydrophilic part. ${ }^{26}$

\section{Adsorption of $\mathrm{C}_{10} \mathrm{E}_{3}$ onto $\mathrm{Na}^{+}-\mathrm{Mt}$}

Several aqueous solutions of $\mathrm{C}_{10} \mathrm{E}_{3}$ were prepared at room temperature below and beyond the $\mathrm{cmc}$ in a wide range of concentrations varying from $2.8 \times 10^{-4}$ to $3.3 \times 10^{-2} \mathrm{~mol} \mathrm{~L}^{-1}$. Below cmc, the $\mathrm{C}_{10} \mathrm{E}_{3}$-water system appeared as an aqueous solution in a monomeric form. For high concentration, above $7.5 \times 10^{-4} \mathrm{~mol} \mathrm{~L}^{-1}$ (experimental $\mathrm{cmc}$ ), the surfactant selfassembles in a lamellar phase $\left(\mathrm{L}_{\alpha}\right)$ which was checked by phase contrast optical microscopy. The solutions were homogenized by stirring at room temperature for several days. $\mathrm{Na}^{+}-\mathrm{Mt}$ in powder form was then dispersed into the surfactant solutions. The average $\mathrm{pH}$ value of the solutions was about $6.5 \pm 0.2$ and remained constant during OC preparation. The obtained dispersions were then stirred for $24 \mathrm{~h}$ at $250 \mathrm{rpm}$. The OC samples, separated by centrifugation, were rinsed with water and dried at $90{ }^{\circ} \mathrm{C}$ for $48 \mathrm{~h}$.

\section{Characterization techniques}

The concentration of carbon in solution was measured using an element analyzer (Shimadzu TOC 5050/SSM 5000-A), which was carried out at the 'Service central de micro-analyse du CNRS' at Solaize in France. The amounts of adsorbed surfactant and equilibrium isotherms were determined on the basis of the concentration decrease after clay mineral impregnation.

Fourier transform infrared (FTIR) measurements in the range $650-4000 \mathrm{~cm}^{-1}$ were performed using a Thermo Nicolet $6700 \mathrm{FT}$ spectrometer equipped with a Deuterated Triglycine Sulfate (DTGS) detector and a Nicolet Continu $\mathrm{m}$ microscope. The powder samples were spread over an $\mathrm{NaCl}$ window of the microscope. The analyzed sample area was a square of side $100 \mu \mathrm{m}$ chosen under the microscope with a $15 \times$ Infinity Reflechromat objective. The analyses were performed in transmission mode and each spectrum was the average of 256 scans collected at $1 \mathrm{~cm}^{-1}$ resolution. FTIR was performed on dry samples $\left(25^{\circ} \mathrm{C}\right.$ under vacuum 2 hours). For the thermal analysis, samples were hold in a FTIR 600 Linkam stage with ZnSe windows.

Small angle X-ray scattering (SAXS) measurements were carried out at the SWING beamline in the SOLEIL Synchrotron source (SOLEIL Synchrotron, Saint-Aubin, Gif-sur-Yvette Cedex, France). The X-ray wavelength used was $1.418 \AA$. The data were recorded using a $17 \mathrm{~cm} \times 17 \mathrm{~cm}$ low-noise CCD-based detector (AVIEX). OC were introduced in an infiltration cell made in the laboratory. Moreover, thermal wide angle diffraction experiments were performed in a conventional $\theta-\theta$ Bragg-Brentano configuration by using a Thermo Electron ARL'XTRA diffractometer equipped with a $\mathrm{Cu}$ anode $\left(\mathrm{CuK}_{\alpha 1,2}=1.5418 \AA\right)$ coupled to a $\mathrm{Si}(\mathrm{Li})$ solid detector. The diffractograms were performed between 1 and $15^{\circ}(2 \theta)$ with an angular and time step of $0.05^{\circ}$ and $10 \mathrm{~s}$ respectively. The samples were put on an alumina sample holder and then heated at $25 \mathrm{~K}$ step-wise in a HTK $1200 \mathrm{~N}$ furnace from Anton Paar. 
The thermogravimetric analyses (TGA) were performed with a SETARAM TGA 92 microanalyser, from 25 to $1100{ }^{\circ} \mathrm{C}$ with a heating rate of $10 \mathrm{~K} \mathrm{~min}^{-1}$. Between 30 and $50 \mathrm{mg}$ of samples were used for each measurement. All samples were held at the same relative humidity before the measurements for a proper comparison between the dehydration peak values.

\section{Results and discussion}

\section{Structure of the $C_{10} E_{3}$ aggregates onto clay mineral surface}

Preparation of nonionic OC was performed in a wide range of concentration when the $\mathrm{C}_{10} \mathrm{E}_{3}$-water system is displayed in monomers and lamellar phase. The experimental cmc previously identified was estimated to be $6 \times 10^{-4} \mathrm{~mol} \mathrm{~L}^{-1}$ whereas a predicted one by knowing the length of the hydrocarbon chain and the number of ethylene oxide groups was determined to be $7.4 \times 10^{-4} \mathrm{~mol} \mathrm{~L}^{-1} \cdot .^{27,28}$ In this study, the lamellar phase occurs at a concentration beyond $7.5 \times 10^{-4} \mathrm{~mol} \mathrm{~L}^{-1}$. It has been recognized that the cmc determination can be performed within a range of uncertainty of few percent, which is in good agreement with the predicted value reinforcing the quality of the developed model. Thus, for a concentration domain below $7.5 \times 10^{-4} \mathrm{~mol} \mathrm{~L}^{-1}$, the amphiphilic molecules are adsorbed on phyllosilicate layers in a monomeric form and lead to behaviors which have been previously observed concerning the adsorption of nonionic surfactants onto clay minerals. ${ }^{12,16}$ Indeed, the adsorption isotherm reveals that the introduced $\mathrm{C}_{10} \mathrm{E}_{3}$ in solution is totally adsorbed on the Mt surface, which suggests the particular affinity of the nonionic surfactant to phyllosilicate layers (Fig. 1). Since, no $\mathrm{Na}^{+}$was found in the resulting solution, the adsorption process does not result in any ion-exchange but involves other interaction mechanisms (hydrogen-bonding, ion-dipole and van der Waals interactions) between surfactant and $\mathrm{Mt}^{10,12,16,17}$ For other regime, adsorption differs when the system is self-organized in a lamellar phase, with the increase of the adsorbed amount of $\mathrm{C}_{10} \mathrm{E}_{3}$ onto $\mathrm{Mt}$ as the concentration of surfactant is increased. Indeed, the line shape of the adsorption

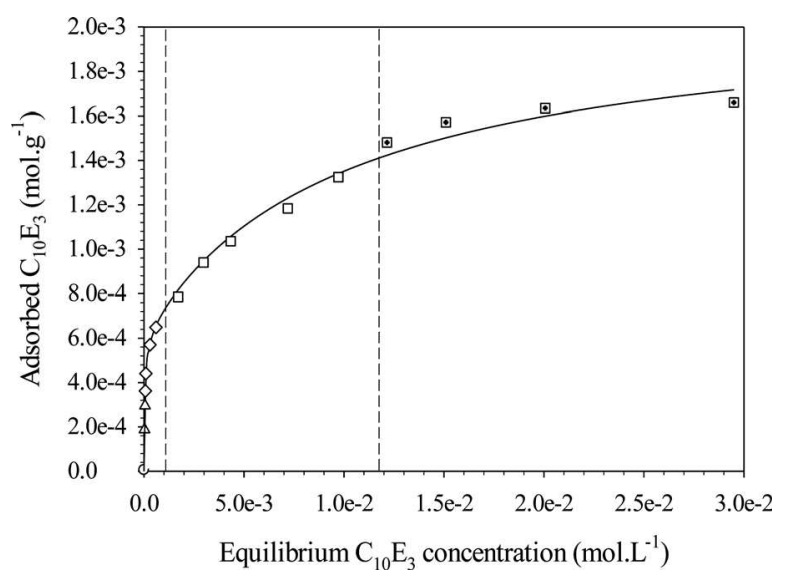

Fig. 1 Adsorption isotherm of $\mathrm{C}_{10} \mathrm{E}_{3}$ below and above $\mathrm{cmc}$ onto $\mathrm{Na}^{+}-\mathrm{Mt}$ (Wyoming). The black line is a guide for the eyes. The dashed line flanks the domain where $\mathrm{C}_{10} \mathrm{E}_{3}$ is confined in a bilayer state within the interlayer space of the nonionic $O C$. isotherm for $\mathrm{C}_{10} \mathrm{E}_{3}$ cannot be fitted by a Langmuir adsorption model equation, successfully used in previous studies, due to a change of the interaction potential induced by the self-organization in a lamellar phase. Moreover, in the sample preparation, $\mathrm{Na}^{+}-\mathrm{Mt}$ is dispersed in individual platelets in suspension of low ionic strength allowing a well adsorption of $\mathrm{C}_{10} \mathrm{E}_{3}$. Breen et al. who studied the adsorption of TX100 pointed similar behavior to a non-saturation of the accessible surface of the clay mineral and suggested that the nonionic polymer was still packing rather than being occluded in the sample preparation. ${ }^{21}$ Here, although the isotherm gradually increases with the equilibrium $\mathrm{C}_{10} \mathrm{E}_{3}$ concentration, at high concentration, a plateau or a steady state can be distinguished that underlines a complete fulfilled of the available adsorption sites leading to a maximum adsorbed $\mathrm{C}_{10} \mathrm{E}_{3}$ value of about $1.6 \times 10^{-3} \mathrm{~mol} \mathrm{~L}^{-1}$.

Moreover to give a qualitative idea on the adsorption process, the FTIR analysis, by focusing on the stretching of both the asymmetric and symmetric $\mathrm{CH}_{2}$ bands, provides information on the molecular environment of the intercalated surfactant (Fig. 2 and 3). Indeed, it is well established that the wavenumber of the $\mathrm{CH}_{2}$ stretching bands of hydrocarbon chains is extremely sensitive to the conformational ordering and change in the gauche-trans conformer ratio of the chains. $^{29,30}$ For highly ordered (all-trans conformation), the characteristics absorption bands are $2916-20 \mathrm{~cm}^{-1}$ for $\mathrm{CH}_{2}$ asymmetric stretching and 2846-50 $\mathrm{cm}^{-1}$ for $\mathrm{CH}_{2}$ symmetric stretching in the infrared spectrum. On the other hand, these two stretching bands shift to higher frequencies and increased widths as the number of gauche conformations along the hydrocarbon chain (chain disorder) increases. Nevertheless, both the intensity and the frequencies of these stretching bands gradually increase with the concentration of $\mathrm{C}_{10} \mathrm{E}_{3}$ while the $d_{001}$ spacing determined by the $00 l$ reflection from the SAXS profile displays a stepwise variation with the surfactant loadings (Fig. 4 and 5). Using the frequency shifts highlighting the

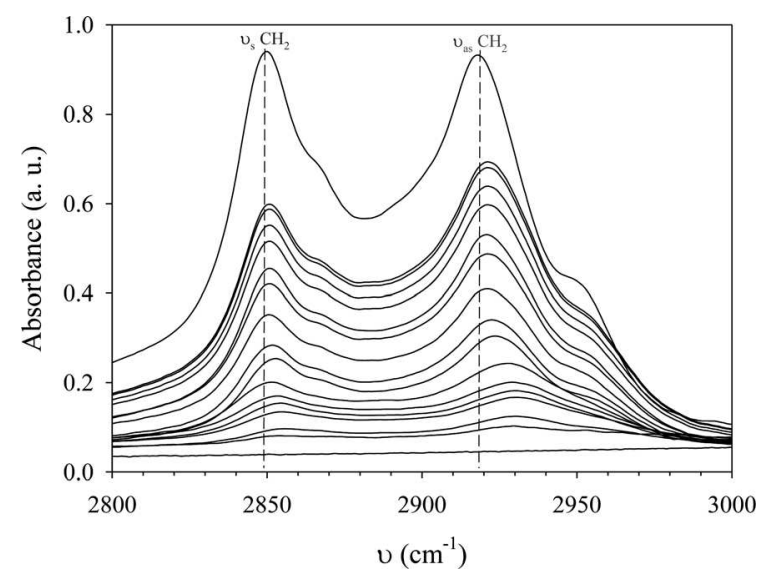

Fig. 2 Progressive growth of the density of the alkyl chains within the interlayer space of Mt. The symmetric and asymmetric $\mathrm{CH}_{2}$ stretching of which wave numbers indicate the presence of disorder/order in the alkyl chains correspond to the two bands. $\mathrm{Na}^{+}-\mathrm{Mt}$ (bottom solid line) and pure $\mathrm{C}_{10} \mathrm{E}_{3}$ (top solid line) also are added. The latter spectrum is reduced by a ratio (divided by 2 ) for a proper visibility in the same window scale. Spectra resolution was $1 \mathrm{~cm}^{-1}$. 


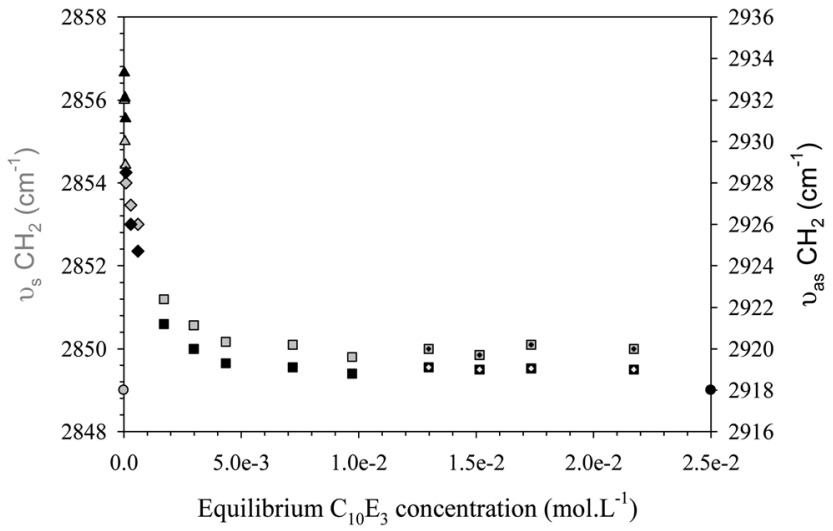

Fig. 3 Representation of the change in frequency of the symmetric and asymmetric $\mathrm{CH}_{2}$ stretching bands of the $\mathrm{C}_{10} \mathrm{E}_{3}-\mathrm{Mt}$ hybrid $\mathrm{OC}$ (circles for bulk $\mathrm{C}_{10} \mathrm{E}_{3}$, triangles for a lateral monolayer arrangement of $C_{10} E_{3}$, lozenge as a lateral bilayer organization, squares for a normal bilayer and black squares for a normal tilted bilayer arrangement respectively) as a function of the equilibrium $C_{10} E_{3}$ concentration.

increase of conformer and the $d_{001}$ spacing variation as a guide, the $\mathrm{C}_{10} \mathrm{E}_{3}$ arrangements within the silicate layers can be determined.

At a low concentration range, below $2 \times 10^{-3} \mathrm{~mol} \mathrm{~L}^{-1}$, the frequencies shift to higher values, 2856 and $2934 \mathrm{~cm}^{-1}$ for the $\mathrm{CH}_{2}$ symmetric and asymmetric bands respectively in comparison to bulk surfactant frequencies (Fig. 3). With decreasing the packing density, the chains are no longer fully stretched in an all-trans conformation but adopt a more disordered structure once adsorbed on the silicate surface. Moreover, considering the anhydrous Mt layer thickness of $9.7 \AA$, determined by the SAXS profile (Fig. 4), the expansion of the interlayer space corresponds to $\sim 4 \AA$, in good agreement with the height of $\mathrm{C}_{10} \mathrm{E}_{3}$ molecules. Thus, below cmc, $\mathrm{C}_{10} \mathrm{E}_{3}$ spreads out on silicate layers in monolayer arrangement (Fig. 6).

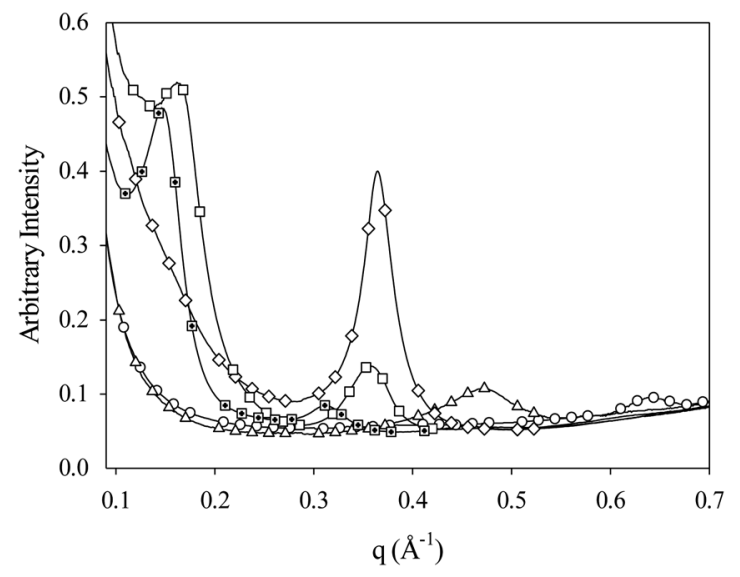

Fig. 4 Small angle $X$-ray scattering (SAXS) profiles for dehydrated $\mathrm{Na}^{+}-\mathrm{Mt}$ (white circles) and $O C$ for four representative $C_{10} E_{3}$ concentration regimes (triangles for a lateral monolayer arrangement of $\mathrm{C}_{10} \mathrm{E}_{3}$, lozenge as a lateral bilayer organization, squares for a normal bilayer and black squares for a normal tilted bilayer arrangement respectively).

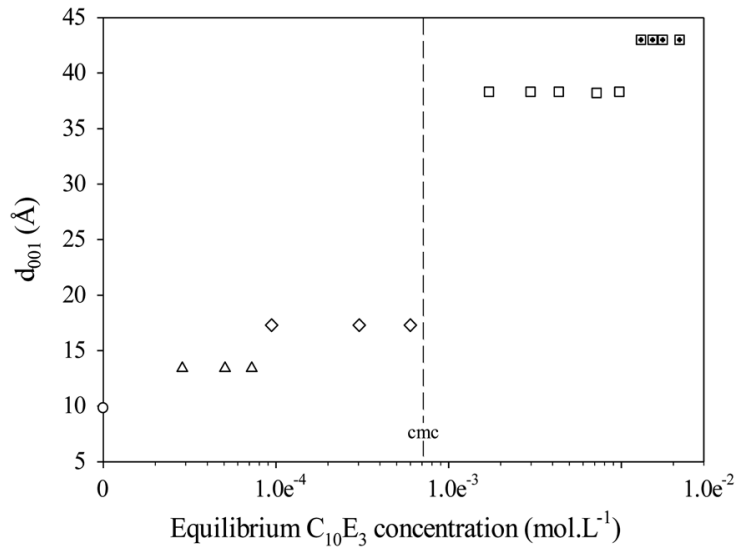

Fig. 5 Evolution of the $d_{001}$ basal spacing determined by the $00 /$ reflection of the silicate sheets obtained from SAXS profiles of $\mathrm{Mt}$ in white circles, and $\mathrm{C}_{10} \mathrm{E}_{3}-\mathrm{Mt}$ hybrid organoclays (triangles for a lateral monolayer arrangement of $C_{10} E_{3}$, lozenge as a lateral bilayer organization, squares for a normal bilayer and black squares for a normal tilted bilayer arrangement respectively) as a function of the equilibrium $\mathrm{C}_{10} \mathrm{E}_{3}$ concentration.

At a concentration range between $9.5 \times 10^{-4}$ and $2 \times$ $10^{-3} \mathrm{~mol} \mathrm{~L}^{-1}$, even if the surfactant self-assembles in a lamellar phase, FTIR and SAXS results support that hydrocarbon chains are not fully stretched in all-trans conformation but may adopt a lateral lying with a disordered structure on the clay mineral surface which is consistent with the $\sim 17.3 \AA$ measured gallery height (Fig. 5). These results indicate that, even if a fraction of the surfactant self-assembles in the membrane, the adsorption mechanism only involves $\mathrm{C}_{10} \mathrm{E}_{3}$ in monomer form rather than an aggregation process as it was predicted. ${ }^{14,15}$ Indeed, Cases and Villieras have modeled the adsorption of nonionic surfactants onto the heterogeneous surface and pointed out that the aggregation mechanism starts below or near the $\mathrm{cmc}$. However, the $\mathrm{C}_{10} \mathrm{E}_{3}$ aqueous solutions were prepared at concentrations close to $\mathrm{cmc}$, where the volume fractions in monomers and the membrane phase are in relative equilibrium. ${ }^{31}$ The volume
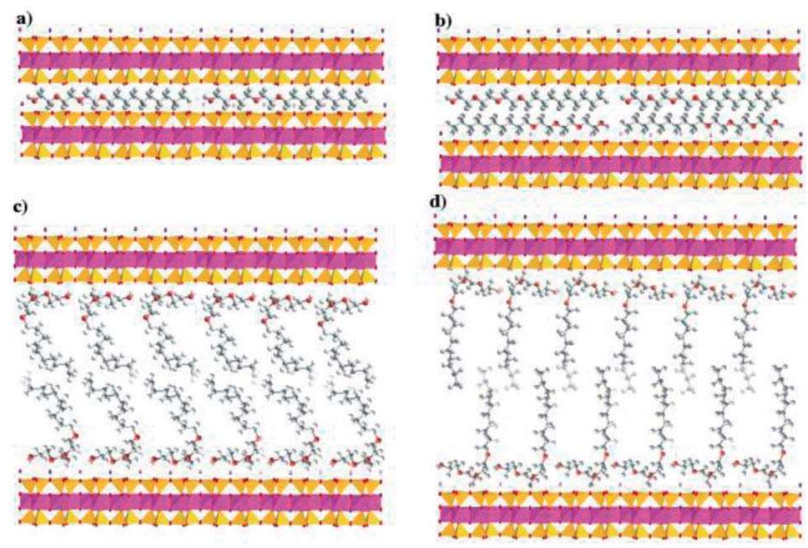

Fig. 6 Structures of the hybrid layered materials for the four concentration regimes: (a) lateral monolayer arrangement; (b) lateral bilayer arrangement; (c) normal bilayer resulting in the condensation of the $L_{\alpha}$ phase; and (d) normal tilted bilayer arrangement. 
fraction of the membrane starts to be preponderant in the system at a concentration $>\sim 3 \mathrm{cmc}$, in which the lamellar phase represents $66 \%$ of the total volume fraction of surfactant in solution. Moreover, it is well established that at such a concentration, bilayers are continuously breaking and reforming and the resulting equilibrium concentration is below $\mathrm{cmc}$, (Fig. 5). Thus, the driving force to merge comes from the reduction in end-cap energies and should be easily disrupted and perturbed with the introduction of clay platelets. Nonionic OC were synthesized at a concentration domain where the surfactant in a monomeric form competes with the self-organized lamellar phase, which is easily disrupted. This mainly favors an adsorption process in monomers leading to a confinement of a lateral bilayer structure parallel to the silicate surface (Fig. 6).

Once the system is mainly assembled in a lamellar phase beyond $3.1 \times 10^{-3} \mathrm{~mol} \mathrm{~L}^{-1}$, for which the resulting equilibrium concentration is above cmc, the adsorption leads to the confinement of a bulk surfactant state in the bilayer of $\mathrm{C}_{10} \mathrm{E}_{3}$, resulting in the aggregation of a bulk lamellar phase, showing a $30^{\circ}$ tilted angle to the clay mineral surface. It is recognized that surfactant in a bulk lamellar phase shows a bilayer thickness generally thinner than the length of two extended molecules. This implicates the existence of a tilt angle between the bilayer surface and the hydrophobic chains of which variation is between $30^{\circ}, 40^{\circ}$ and even $60^{\circ} .^{26,32}$ As it has been previously explained, there is not a perfect match between the crosssectional area of the extended molecules $\left(0.76 \mathrm{~nm}^{2}\right)$ and the available mineral surface to surfactant molecule ratio (0.9$1.5 \mathrm{~nm}^{2}$ ). At such a concentration, with a silicate surface incompletely covered, the aggregation of surfactant in bilayer, resulting in lateral hydrophobic interactions between chains, leads to a more freedom and a stronger mobility of the alkyl chains, which increase consequently the disorder and gauche conformer, and thus explains the small observed frequency shift.

Beyond a concentration of $1.3 \times 10^{-2} \mathrm{~mol} \mathrm{~L}^{-1}$, adsorption excludes any monomer process and results in a bilayer aggregation mechanism. The whole phyllosilicate layer surface is totally taken up, highlighted by the observation of a plateau in the adsorption isotherm. However, even for these high concentrations, both frequencies of $\mathrm{CH}_{2}$ stretching vibrations never reach the values corresponding to the three-dimensional order that they had in bulk $\mathrm{C}_{10} \mathrm{E}_{3}$ (Fig. 3). The confinement in a slit of few nanometers between phyllosilicate layers and the presence of long range electrostatic interaction may explain the small shift in frequencies which has been previously identified for numerous similar systems based on clay minerals where the observation of the gauche conformer has been recognized to be ubiquitous. $^{30}$ Nevertheless, with such packing density, the chains are predominantly extended normal to the surface with an all-trans conformation. In such a configuration, there is a narrow match between the packing area per molecule and the ratio of the available specific surface area of $\mathrm{Na}^{+}-\mathrm{Mt}$ to invite surfactant molecules. Moreover, the presence of extended chains normal to the surface is further supported by the observed measured interlayer space at about $43 \AA$. A bilayer arrangement with a fully stretched chain, as Fig. 6 shows, tilted of $90^{\circ}$ (angle of $90^{\circ}$ to the clay mineral surface) with respect to the clay mineral surface seems likely, since the expansion of the interlayer corresponds to such re-organization of the chains. Numerous studies on the adsorption of cationic surfactants have highlighted the reorganization of the confined surfactant molecules, which optimized the occupation of the accessible clay mineral surface by showing a tilt angle to the phyllosilicate layers surface. This tilt angle gradually increases following the loading of surfactants, until reaching an angle of $90^{\circ}$, i.e. the surfactant hydrocarbon chains are perpendicular to the clay mineral surface. ${ }^{33}$ It is interesting to point out the discrete variation of the interlayer space, which differs from cationic OC and may be explained by different adsorption mechanisms between surfactants and the Mt surface.

\section{Thermal stability of the $\mathrm{C}_{10} \mathrm{E}_{3}-\mathrm{Mt}$ OC materials}

The $\mathrm{C}_{10} \mathrm{E}_{3}-\mathrm{Mt}$ OC materials have the main property of maintaining the charge characteristics of the inorganic layered Mt. Thus, the presence of $\mathrm{Na}^{+}$within the interlayer space, despite the intercalation of non-ionic surfactants, confers to dual hydrophobic-hydrophilic behavior. Indeed, the intercalation of surfactant leads to a hydrophobic character whereas the preservation of $\mathrm{Na}^{+}$cations within the interlayer space, probed by an ICP technique, drives to a hydrophilic character. Such dual behavior has been observed for the adsorption of micropollutants showing different chemical nature. ${ }^{34}$ Moreover, the distinct arrangements of $\mathrm{C}_{10} \mathrm{E}_{3}$ in lateral layers, a normal bilayer or paraffin like structure, in contrast to previous non-ionic organic compounds used for which only lateral monolayers were confined, allow us to modulate the opening of the interlayer space at several values for further experiments such as the exfoliation of such hybrid layered materials as fillers in the polymer matrix. In this latter case, $\mathrm{C}_{10} \mathrm{E}_{3}$ shows both better chemical and thermal stabilities than the conventional alkylammonium salts, usually used for the preparation of OC, which are usually thermally degraded around $200{ }^{\circ} \mathrm{C}$, temperature for which the extrusion of the polymer is achieved, leading to undesirable color, odor and taste, and also degrade the properties of the polymer nanocomposite. ${ }^{35,36}$ Beyond these potential applications and uses of $\mathrm{C}_{10} \mathrm{E}_{3}-\mathrm{Mt}$ organoclays, the assessments of the thermal stability and properties of the hybrid materials provide relevant information on the portions of $\mathrm{C}_{10} \mathrm{E}_{3}$ in close interaction with the Mt surface. ${ }^{21,37-39}$

The thermogravimetric analysis (TGA) from 25 to $1000{ }^{\circ} \mathrm{C}$ shows similar features between the $\mathrm{Na}^{+}-\mathrm{Mt}$ and the $\mathrm{C}_{10} \mathrm{E}_{3}-\mathrm{Mt}$ organoclays (Fig. 7): (i) a weight loss and the endothermic peak (not shown) at $650-800{ }^{\circ} \mathrm{C}$ is associated with the dehydroxylation of the Mt layers and (ii) the loss of adsorbed water which occurs at the temperature around $100{ }^{\circ} \mathrm{C}$. However, while such loss of water usually occurs at $100^{\circ} \mathrm{C}$ and even more for raw $\mathrm{Mt}$, previous studies reported that, for OC prepared by conventional cationic surfactants, the hydrophobicity resulting in both the introduction and arrangement of surfactants within the interlayer space affects the temperature for the loss of adsorbed water. ${ }^{37,38,40}$ Such behavior is not observed here with no shift to low temperature for the loss of adsorbed water once $\mathrm{C}_{10} \mathrm{E}_{3}$ is 


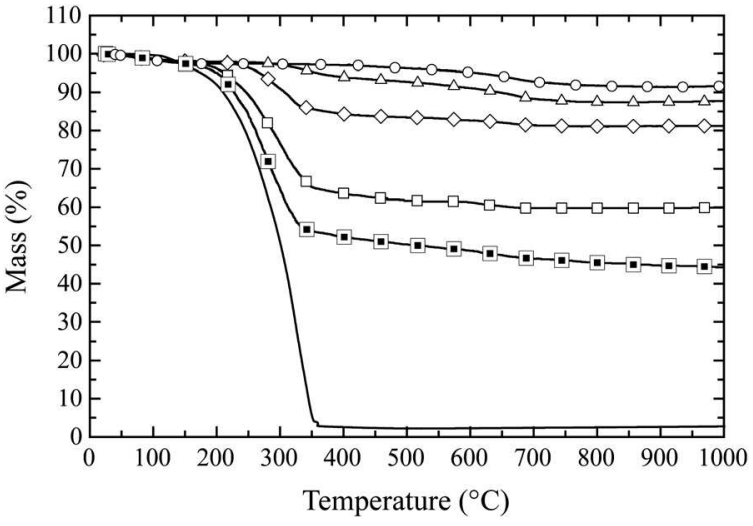

Fig. 7 Thermograms of Na-Mt (white circles), $C_{10} E_{3}-M t$ hybrid organoclays (triangles for a lateral monolayer arrangement of $\mathrm{C}_{10} \mathrm{E}_{3}$, lozenge as a lateral bilayer organization, squares for a normal bilayer and black squares for a normal tilted bilayer arrangement respectively) and bulk $\mathrm{C}_{10} \mathrm{E}_{3}$ (solid line).

intercalated. Although the content of water in the samples is rather small (less than $3 \%$ ), this underlines that $\mathrm{C}_{10} \mathrm{E}_{3}$ does not affect the interaction between water and the Mt surface (Table 1). Nevertheless, compared to the raw Mt, in the temperature range $200-350{ }^{\circ} \mathrm{C}$, a strong weight loss is observed for $\mathrm{C}_{10} \mathrm{E}_{3}-\mathrm{Mt}$ OC which can be attributed to the decomposition of $\mathrm{C}_{10} \mathrm{E}_{3}$ (Fig. 7).

In contrast to the bulk $\mathrm{C}_{10} \mathrm{E}_{3}$ decomposition temperature of $305{ }^{\circ} \mathrm{C}$ determined by the exothermic peak, those of $\mathrm{C}_{10} \mathrm{E}_{3}$ confined in the layered structure spread out in a wide range of temperature $\left(280-350{ }^{\circ} \mathrm{C}\right)$ which depend on both the density and arrangement of the intercalated surfactant (Table 1). Indeed, it appears that the thermal stability is disrupted with the density of $\mathrm{C}_{10} \mathrm{E}_{3}$ in the interlayer space whereas it is reinforced for small loading of $\mathrm{C}_{10} \mathrm{E}_{3}$. Although the surfactants used are chemically different, a comparison with a previous reference thermal study of OC with alkyl-ammonium salts revealed that similar observation concerning the density of the intercalated surfactant impacted the breaking down of the surfactant with a downward shift of $50{ }^{\circ} \mathrm{C}$ between small and high loadings. ${ }^{37}$ For a lateral monolayer arrangement (i.e. small loading of $\mathrm{C}_{10} \mathrm{E}_{3}$ $<10 \%$ ), the whole portions of $\mathrm{C}_{10} \mathrm{E}_{3}$ are in close interaction with the Mt surface, conferring strong effects of confinement which drives to a better thermal stability and a upward shift of $50{ }^{\circ} \mathrm{C}$ for the decomposition temperature comparatively to the bulk. ${ }^{41,42}$ For other arrangements, more particularly in paraffin like structure, intermolecular interactions induce collective effects, which contribute to affect molecular dynamics, while interaction with the Mt surface and the presence of electrostatic interaction between silicate layers perturb as well confined $\mathrm{C}_{10} \mathrm{E}_{3}$. The combination of these antagonist effects disrupts the decomposition temperature with a downward shift, which seems to be higher for a bilayer aggregation arrangement.

Although using different sample chambers, the differences of the $\mathrm{C}_{10} \mathrm{E}_{3}-\mathrm{Mt}$ OC observed in the thermogravimetric data are also reflected in both thermal XRD and FTIR analyses (Fig. 8 and 10). By following the $d_{001}$ basal spacing, determined through the $00 l$ reflections of the hybrid layered materials, as well as the frequencies of both the asymmetric and symmetric $\mathrm{CH}_{2}$ stretching bands, a change of $\mathrm{C}_{10} \mathrm{E}_{3}$ organization with temperature can be highlighted (Fig. 9 and 11).

Since $\mathrm{C}_{10} \mathrm{E}_{3}$ self-organizes in lateral or normal bilayers (tilted or not) within the interlayer space, its arrangement changes at temperatures around $175-200{ }^{\circ} \mathrm{C}$ which can be identified with the collapse of the interlayer space. This $d_{001}$ spacing contraction of the whole samples, except the OC for which only a lateral monolayer of surfactant is intercalated, appears in a temperature range where a large part of gauche conformers is measured (Fig. 11). In this latter case, the fast mobility of the alkyl tails as well as the decrease of $\mathrm{C}_{10} \mathrm{E}_{3}$ density, which can be identified by

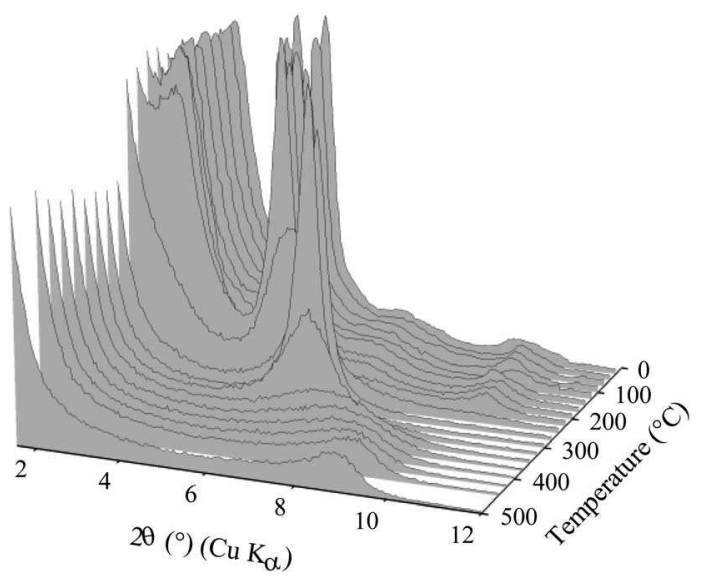

Fig. 8 Variable temperature $X$-ray diffractograms for $\mathrm{C}_{10} \mathrm{E}_{3}-\mathrm{Mt}$ with a loading of $2.02 \times 10^{-2} \mathrm{~mol} \mathrm{~L}^{-1}$ (normal tilted bilayer arrangement).

Table 1 Thermo-analytical characteristics of the $\mathrm{Na}^{+}-\mathrm{Mt}$, bulk $\mathrm{C}_{10} \mathrm{E}_{3}$ nonionic surfactant and the resulting OC obtained for 4 concentrations showing distinct surfactant arrangement within the interlayer space

\begin{tabular}{|c|c|c|c|c|c|c|}
\hline Samples & Basal spacing $(\mathrm{nm})$ & \multicolumn{2}{|l|}{ Adsorbed water } & \multicolumn{2}{|l|}{ Desurfactant } & Organic content $(\%)$ \\
\hline $\mathrm{C}_{10} \mathrm{E}_{3}-\mathrm{Mt}\left(5.07 \times 10^{-5} \mathrm{~mol} \mathrm{~L}^{-1}\right)$ & 1.34 & 2.1 & 103 & 4.6 & 347 & 5.2 \\
\hline $\mathrm{C}_{10} \mathrm{E}_{3}-\mathrm{Mt}\left(3.03 \times 10^{-5} \mathrm{~mol} \mathrm{~L}^{-1}\right)$ & 1.73 & 1.8 & 103 & 14.1 & 303 & 15.2 \\
\hline $\mathrm{C}_{10} \mathrm{E}_{3}-\mathrm{Mt}\left(4.34 \times 10^{-3} \mathrm{~mol} \mathrm{~L}^{-1}\right)$ & 3.67 & 2.0 & 102 & 35.9 & 295 & 37.7 \\
\hline
\end{tabular}




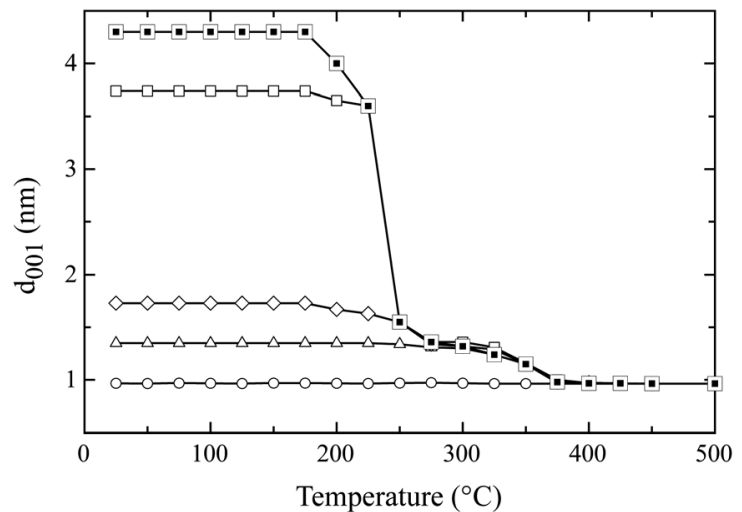

Fig. 9 Change of the $d_{001}$ basal spacings (nm) of Na+-Mt (white circles), and $\mathrm{C}_{10} \mathrm{E}_{3}-\mathrm{Mt}$ hybrid $\mathrm{OC}$ (triangles for a lateral monolayer arrangement of $\mathrm{C}_{10} \mathrm{E}_{3}$, lozenge as a lateral bilayer organization, squares for a normal bilayer and black squares for a normal tilted bilayer arrangement respectively) as a function of the temperature $\left({ }^{\circ} \mathrm{C}\right)$

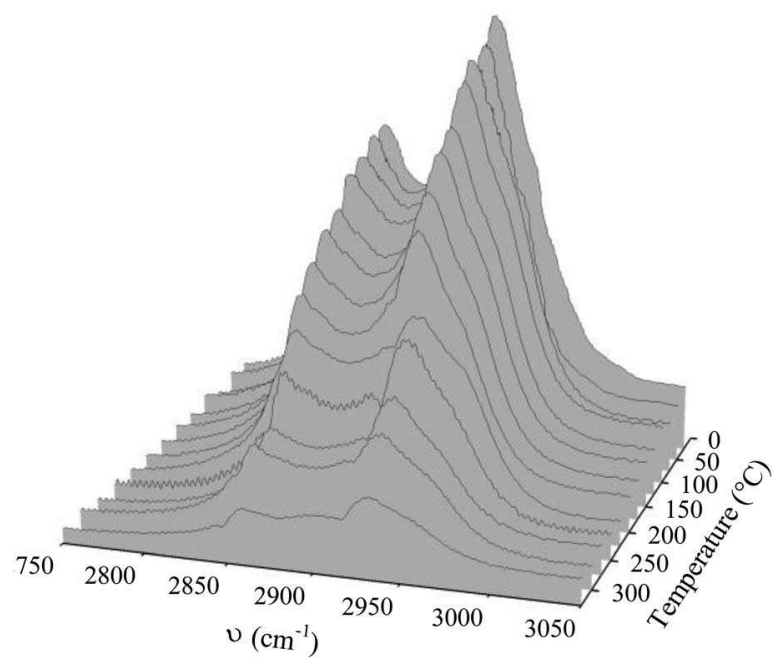

Fig. 10 Variable temperature FTIR spectra in the $\mathrm{CH}_{2}$ stretching frequencies for $\mathrm{C}_{10} \mathrm{E}_{3}-\mathrm{Mt}$ with a loading of $2.02 \times 10^{-2} \mathrm{~mol} \mathrm{~L}^{-1}$ (normal tilted bilayer arrangement).

the decrease of the $\mathrm{CH}_{2}$ stretching bands, may explain the collapse of the interlayer space. Another stepwise decrease can be observed once the temperature reaches $225-250{ }^{\circ} \mathrm{C}$, for which all-trans conformation (i.e. normal bilayer arrangement) switches to lateral arrangement with gauche conformers in the hydrocarbon chains. Then, for a temperature above $250{ }^{\circ} \mathrm{C}$, all $\mathrm{C}_{10} \mathrm{E}_{3}-\mathrm{Mt}$ organoclays show a lateral surfactant monolayer arrangement of which for some of the samples the previous thermal treatment may have degraded some portions of $\mathrm{C}_{10} \mathrm{E}_{3}$.

The thermal FTIR analysis permits the identification of the $\mathrm{C}_{10} \mathrm{E}_{3}$ portions in close interaction with the Mt surface. The thermal treatment disrupts the conformation of the confined $\mathrm{C}_{10} \mathrm{E}_{3}$ with a change of its arrangement but also degrades first the hydrocarbon chains. Indeed, the intensity of the $\mathrm{CH}_{2}$ stretching absorption bands gradually decreases as the temperature is increased, and no intensity can be observed for a
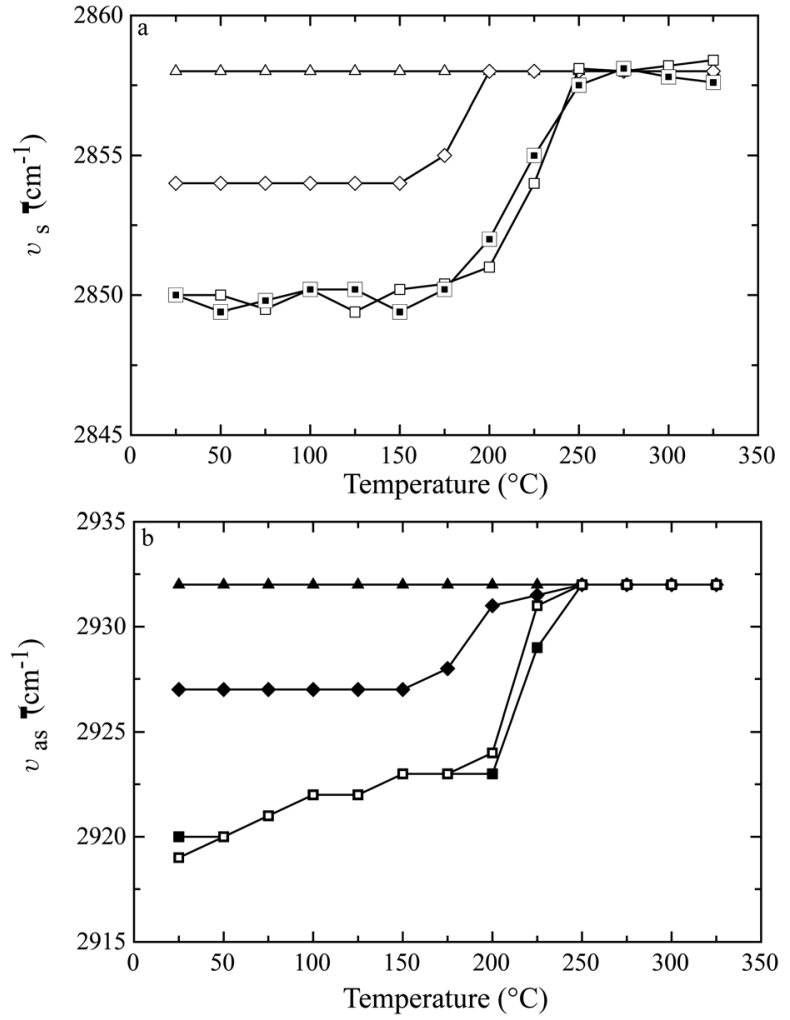

Fig. 11 Representation of the change in frequency of (a) the symmetric and (b) asymmetric $\mathrm{CH}_{2}$ stretching bands of the $\mathrm{C}_{10} \mathrm{E}_{3}-\mathrm{Mt}$ hybrid $\mathrm{OC}$ (triangles for a lateral monolayer arrangement of $\mathrm{C}_{10} \mathrm{E}_{3}$, lozenge as a lateral bilayer organization, squares for a normal bilayer and black squares for a normal tilted bilayer arrangement respectively) as a function of the temperature $\left({ }^{\circ} \mathrm{C}\right)$.

temperature above $325^{\circ} \mathrm{C}$. As a result, for high temperature (i.e. $>350{ }^{\circ} \mathrm{C}$ ), the hydrophobic portion of $\mathrm{C}_{10} \mathrm{E}_{3}$ may be completely degraded while the layers for both samples collapse to a $13 \AA$ spacing which suggests that $\mathrm{C}_{10} \mathrm{E}_{3}$ has not been completely expelled from the interlayer space. Breen et al. pointed out similar observation for the adsorption of TX100 onto several clay minerals with an early thermal decomposition of the alkyl tails of the intercalated nonionic polymer comparatively to the hydrophilic head groups which were degraded at a upward $50{ }^{\circ} \mathrm{C}$ shift. ${ }^{21}$ However, FTIR spectra in this temperature range cannot provide any clear evidence of $\mathrm{C}-\mathrm{O}$ and $\mathrm{O}-\mathrm{H}$ absorption bands, the XRD patterns show the presence of confined organic matter corresponding to the hydrophilic ethylene oxide portion in which the close interaction with the Mt surface prevents any thermal decomposition at the same temperature as other portions of surfactant weakly held.

\section{Conclusions}

In this study, $\mathrm{C}_{10} \mathrm{E}_{3}$ was successfully intercalated within the interlayer space of montmorillonite probably by interaction with the Mt surface as well as with the sodium exchangeable cations, which are kept during the adsorption, conferring dual hydrophilic-hydrophobic behavior for the resulting organoclays. Both the affinity and the final arrangement of $\mathrm{C}_{10} \mathrm{E}_{3}$ 
depend on its phase state in aqueous solution, the self-assembled lamellar phase drives to the condensation of normal bilayers onto the Mt surface expanding the interlayer space at wide values whereas $\mathrm{C}_{10} \mathrm{E}_{3}$ in isolated molecules leads to lateral layer arrangements as it has been observed in previous research studies. The thermal stability of the layered organoclays prepared by $\mathrm{C}_{10} \mathrm{E}_{3}$ has been found to be dependent upon the surfactant arrangement in that intercalated lateral monolayer where a strong effect of confinement imparts greater thermal preservation than those containing normal bilayer arrangements. The conformation of the confined $\mathrm{C}_{10} \mathrm{E}_{3}$ revealed the introduction of gauche conformers with temperature and a loss of density of the hydrocarbon chains, which are firstly degraded contracting the basal spacing of the hybrid layered materials.

\section{Acknowledgements}

The author Régis Guégan would like to thank the Canon Foundation for their support during his stay at the University of Waseda, and M. Ogawa and F. Bergaya for fruitful discussions. SAXS experiments were performed at the SOLEIL Synchrotron Facility (CNRS, Saint-Aubin, France). The assistance of F. Meneau during this project was particularly appreciated.

\section{Notes and references}

1 H. Heinz and U. W. Suter, Angew. Chem., Int. Ed., 2004, 43, 2239-2243.

2 C. Richard, F. Balavoine, P. Schultz, T. W. Ebbesen and C. Mioskowski, Science, 2003, 300, 775-778.

3 M. J. Rosen, Surfactants and interfacial phenomena/Milton J. Rosen, Wiley, New York, 1978.

4 W. A. Ducker and L. M. Grant, J. Phys. Chem., 1996, 100, 11507-11511.

5 W. A. Ducker and E. J. Wanless, Langmuir, 1998, 15, 160-168.

6 M. Jaschke, H. J. Butt, H. E. Gaub and S. Manne, Langmuir, 1997, 13, 1381-1384.

7 S. Manne, J. P. Cleveland, H. E. Gaub, G. D. Stucky and P. K. Hansma, Langmuir, 1994, 10, 4409-4413.

8 G. Srinivas, S. O. Nielsen, P. B. Moore and M. L. Klein, J. Am. Chem. Soc., 2005, 128, 848-853.

9 S. Balme, R. Guegan, J.-M. Janot, M. Jaber, M. Lepoitevin, P. Dejardin, X. Bourrat and M. Motelica-Heino, Soft Matter, 2013, 9, 3188-3196.

10 R. Guégan, Langmuir, 2010, 26, 19175-19180.

11 R. Guégan, J. Colloid Interface Sci., 2011, 358, 485-490.

12 R. Guégan, M. Gautier, J.-M. Beny and F. Muller, Clays Clay Miner., 2009, 57, 502-509.

13 Y. Iwashita and H. Tanaka, Phys. Rev. Lett., 2005, 95, 047801. 14 P. Levitz, Langmuir, 1991, 7, 1595-1608.

15 J. M. Cases and F. Villieras, Langmuir, 1992, 8, 1251-1264.
16 Y. Deng, J. B. Dixon and G. N. White, Clays Clay Miner., 2003, 51, 150-161.

17 Y. Deng, J. Dixon and G. N. White, Colloid Polym. Sci., 2006, 284, 347-356.

18 C.-C. Su and Y.-H. Shen, Colloids Surf., A, 2008, 312, 1-6.

19 C.-C. Su and Y.-H. Shen, J. Colloid Interface Sci., 2009, 332, 11-15.

20 E. Finocchio, I. Baccini, C. Cristiani, G. Dotelli, P. Gallo Stampino and L. Zampori, J. Phys. Chem. A, 2011, 115, 7484-7493.

21 C. Breen, G. Thompson and M. Webb, J. Mater. Chem., 1999, 9, 3159-3165.

22 D. M. Fox, P. H. Maupin, R. H. Harris, J. W. Gilman, D. V. Eldred, D. Katsoulis, P. C. Trulove and H. C. De Long, Langmuir, 2007, 23, 7707-7714.

23 C. Wan, F. Zhao, X. Bao, B. Kandasubramanian and M. Duggan, J. Phys. Chem. B, 2008, 112, 11915-11922.

24 P. L. Hall and D. M. Astill, Clays Clay Miner., 1989, 37, 355363.

25 M. Gautier, F. Muller, L. Le Forestier, J. M. Beny and R. Guegan, Appl. Clay Sci., 2010, 49, 247-254.

26 C. Tanford, J. Phys. Chem., 1972, 76, 3020-3024.

27 J. M. Corkill, J. F. Goodman and S. P. Harrold, Trans. Faraday Soc., 1964, 60, 202-207.

28 P. D. T. Huibers, V. S. Lobanov, A. R. Katritzky, D. O. Shah and M. Karelson, Langmuir, 1996, 12, 1462-1470.

29 Y. Li and H. Ishida, Langmuir, 2003, 19, 2479-2484.

30 R. A. Vaia, R. K. Teukolsky and E. P. Giannelis, Chem. Mater., 1994, 6, 1017-1022.

31 A. D. Mackie, A. Z. Panagiotopoulos and I. Szleifer, Langmuir, 1997, 13, 5022-5031.

32 Y. Tsori and D. Andelman, J. Chem. Phys., 2001, 115, 19701978.

33 Y. Xi, R. L. Frost and H. He, J. Colloid Interface Sci., 2007, 305, 150-158.

34 R. Guégan et al., unpublished.

35 G. W. Beall and M. Goss, Appl. Clay Sci., 2004, 27, 179-186.

36 E. Hablot, P. Bordes, E. Pollet and L. Avérous, Polym. Degrad. Stab., 2008, 93, 413-421.

37 C. B. Hedley, G. Yuan and B. K. G. Theng, Appl. Clay Sci., 2007, 35, 180-188.

38 Y. Xi, Q. Zhou, R. L. Frost and H. He, J. Colloid Interface Sci., 2007, 311, 347-353.

39 S. Yariv, Thermochim. Acta, 1996, 274, 1-35.

40 F. Kooli, Y. Liu, S. F. Alshahateet, M. Messali and F. Bergaya, Appl. Clay Sci., 2009, 43, 357-363.

41 R. Guégan, D. Morineau, R. Lefort, W. Béziel, M. Guendouz, L. Noirez, A. Henschel and P. Huber, Eur. Phys. J. E: Soft Matter Biol. Phys., 2008, 26, 261-273.

42 R. Guégan, D. Morineau, C. Loverdo, W. Béziel and M. Guendouz, Phys. Rev. E: Stat., Nonlinear, Soft Matter Phys., 2006, 73, 011707. 